\title{
Moral Disengagement and Aggression in Fight Sport Athletes
}

\author{
Burcu Güvendi ${ }^{1}$, Ayşe Türksoy Işım ${ }^{1}$ \\ ${ }^{1}$ Istanbul University Cerrahpasa, Faculty of Sport Sciences \\ Correspondence: Burcu Güvendi, Istanbul University Cerrahpasa, Faculty of Sport Sciences, Turkey.
}

Received: May 5, 2019

Accepted: June 2, 2019

Online Published: June 5, 2019

doi:10.11114/jets.v7i7.4244

URL: https://doi.org/10.11114/jets.v7i7.4244

\begin{abstract}
The goal of this study is to investigate the moral disengagement and aggression levels of fight sport athletes according to several independent variables and reveal the relationship among them. The study group consisted of totally 207 fight sport athletes, 88 females and 119 males with age $\underline{X}=21,99 \pm 4,92$ and year of sport $\underline{X}=6,14 \pm 5,42$. "The Scale of Moral Disengagement in Sport" and "The Questionnaire of Buss-Perry Aggression" were used as data collection tools. Descriptive statistics, $t$ test, ANOVA and Pearson Correlation analysis were used in the analysis of data. While the mean of physical aggression of athletes was found as the highest, verbal aggression had the lowest mean value within the sub-dimensions of aggression, and they stated that they somewhat disagreed with the moral disengagement. It was found that there was a moderate positive significant correlation between moral disengagement and sub-dimensions of anger, hostility, physical and verbal aggressions of aggression scale. Significant difference was observed in the dimension of moral disengagement in accordance with age and year of sport. Physical and verbal aggression scores of males are significantly higher according to gender. The aggression and moral disengagement scores of kickboxers are significantly higher than those of taekwondo athletes in line with the branch. To conclude, it was determined that fight sport athletes did not approve moral disengagement in sport, however, the case of moral disengagement of athletes, who were younger and started the sport recently, was higher and they mostly showed the behaviour of aggression physically.
\end{abstract}

Keywords: moral disengagement, aggression

\section{Introduction}

Sport and moral values are in indirect relation with each other. The principles and characteristics that determine the sport also establish the morals or life style (Tel, 2014). Moral principles are defined as the rules of morals, which is characterised as rules, limitations and evaluations that regulate people's attitudes and behaviours, organising the relationships between people (Yildirim, 2016). Morals should be considered as an element not to be ignored within the virtues that sport develops in society (Arslan, 2018). Sports or physical activity are fields of which positive effects on societies and character is continuously drawn attention. However, when the individual decision-making process is in question, a number of moral deficiencies and negative situations related to the character are seen in this field (Gorgut and Tuncel, 2017). Violence and aggression and aberrant behaviours in sports are increasing today on the contrary to the days when the sports fields and areas were called the temple of peace, brotherhood and love. This situation that was led by more than one factor causes all the people in the sport to start to feel discomfort (Yucel, Atalay and Gurkan, 2015). Aggression and acts of violence are also important in sports. Although the occurrence of these events is considered as incompatible with sports at first sight, those who are involved in these events find various reasons for their behaviours. Nevertheless, it is always emphasized that sport is or should be "peace, brotherhood, friendship" and brings societies closer (Ozbaydar, 1983). The act of aggression is a concept that has a negative impact on athlete and athletic success. In recent years, aggressive behaviours in sports halls, schools and stadiums in our country increase day by day (Yıldırım and Abakay, 2015). It is clear that sport is highly variable, has transformed from amateur activity into a professional work like a job. It is observed that the broad economic and political interests offered by the gold medals or the performances of record-holder athletes lead to an increasing competition between the athletes (Hemphill, 2009). Sport's being indeed a game and its nature of overshadowing negativity as in other games has begun to get deformed, and being at the top and staying there became the primary goal at all costs. Therefore, the point that sport has today come raises the suspicion that whether it is no longer a suitable tool for education of values/ethics (Abanoz \& Soyer, 2018). Martial arts such as boxing and kickboxing has recently started to be performed professionally in our country as in the whole world and this increased the interest in all sports that can be accepted under the name of martial sports. This interest also affects the number of 
scientific studies related to martial sports (Tekin, Aykora, Bozacı and Eliöz, 2010). Shields, Funk and Bredemeier (2015) stated that there is a negative relationship between moral disengagement and empathy, and gender, who the refusers are and moral identity structures are significant determinants of morals and concluded that the participants of the study are less morally cautious in sport than in daily life. It can be seen in the study by Garay, Carrasco and Amor (2016) that the relationship between anger, hostility and aggression is mediated by moral disengagement. According to Johnson, Vargas, Watson, Pedersen (2018), most coaches indicated that hostile aggression was never unacceptable or justified, and the most common results of hostile aggression in athletes were detected as reduced playing time and additional physical conditioning. Albouza, d'Arripe-Longueville, Corrion (2017) argued in their study that moral values have relationship to aggression. It should be revealed that how to do the impulses like aggression that are inherent in the nature of martial sports reflect to the behaviours of athletes and their way of showing these. In this manner, the goal of this study is to investigate the moral disengagement and aggression levels of fight sport athletes according to several independent variables and reveal the relationship among them.

\section{Materials and Methods}

\subsection{Population and Sample}

Relational survey model, from the general survey model conducted on all population or a sample taken from it with the aim of making a general judgment about the population consisting of many elements, aiming to determine the presence or degree of covariance between two or more variables has been used (Karasar, 2012). The study group consisted of totally 207 fight sports athletes, 88 females and 119 males with age $\underline{X}=21,99 \pm 4,92$ and year of sport $\underline{X}=6,14 \pm 5,42$.

\subsection{Data Collection Tools}

"The Scale of Moral Disengagement in Sport" and "The Questionnaire of Buss-Perry Aggression" were used as data collection tools.

\subsubsection{The Scale of Moral Disengagement in Sport}

The short form of the Scale of Moral Disengagement in Sport (MDSSS) that was developed by Boardley and Kavussanu (2008) was adapted to Turkish by Gurpinar (2015). It is a 7 point Likert-type scale scored as Strongly Disagree (1), Disagree (2), Somewhat Disagree (3), Neutral (4), Somewhat Agree (5), Agree (6), Strongly Agree (7). The scale has 8 items and single factor. All items for measuring the attitudes of moral disengagement in sports have negative meaning. The high scores of scale mostly mean that athletes do not obey the rules of morals more (Gurpinar, 2015).

\subsubsection{Buss Perry Aggression Questionnaire}

Turkish validity and reliability study of Buss Perry Aggression Questionnaire that was developed by Buss and Perry (1992) was conducted by Madran (2012). Its Turkish form coincides with its original one and consists of totally four dimensions and 29 items as follow: (a) Physical aggression $\left(13^{\text {th }}, 8^{\text {th }}, 2^{\text {nd }}, 11^{\text {th }}, 25^{\text {th }}, 16^{\text {th }}, 29^{\text {th }}, 22^{\text {nd }}\right.$ and $5^{\text {th }}$ items $)$; (b) Hostility $\left(20^{\text {th }}, 24^{\text {th }}, 3^{\text {rd }}, 26^{\text {th }}, 10^{\text {th }}, 15^{\text {th }}, 7^{\text {th }}\right.$ and $17^{\text {th }}$ items $) ;$ c) Anger $\left(19^{\text {th }}, 28^{\text {th }}, 1^{\text {st }}, 18^{\text {th }}, 9^{\text {th }}, 23^{\text {rd }}\right.$ and $12^{\text {th }}$ items $)$; and (d) Verbal aggression $\left(27^{\text {th }}, 6^{\text {th }}, 21^{\text {st }}, 14^{\text {th }}\right.$ and $4^{\text {th }}$ items $)$

\subsection{Data Analysis}

Descriptive statistics, t-test, Single Factor Variance Analysis (ANOVA) and Pearson Moments Product Correlation analysis were used in the analysis of data.

\section{Results}

The results of this study conducted with the purpose of investigating the moral disengagement and aggression levels of fight sport athletes according to several independent variables and reveal the relationship among them are as follows.

Table 1. The Mean Scores of Scales

\begin{tabular}{lrrrr}
\hline & $\mathrm{n}$ & Min. & Max. & Mean \pm Std. Dev. \\
\hline Physical Aggression & 207 & 9,00 & 38,00 & $19,69 \pm 6,26$ \\
Anger & 207 & 7,00 & 32,00 & $16,80 \pm 5,26$ \\
Hostility & 207 & 8,00 & 36,00 & $19,25 \pm 5,68$ \\
Verbal Aggression & 207 & 5,00 & 22,00 & $12,12 \pm 3,92$ \\
Moral Disengagement & 207 & 1,00 & 7,00 & $2,73 \pm 1,14$ \\
\hline
\end{tabular}

Table 1 shows that while the mean of physical aggression and hostility of athletes was found as the highest, verbal aggression had the lowest mean value within the sub-dimensions of aggression, and they somewhat stated that they disagreed with the moral disengagement. 
Table 2. Anova Analysis Results of Moral Disengagement and Aggression Scale According to Age Variable

\begin{tabular}{lrrrrrr}
\hline & Age & $\mathrm{n}$ & Mean \pm Std. Dev. & F & p & Tukey \\
\hline \multirow{3}{*}{ Moral } & $17-18$ & 59 & $25,525 \pm 10,685$ & & & \\
Disengagement & $19-20$ & 45 & $19,866 \pm 8,108$ & & & $17-18 / 19-20$ \\
& $21-22$ & 41 & $19,707 \pm 8,234$ & 4,907 &, $003 *$ & $17-18 / 21-22$ \\
& 23 and above & 62 & $21,371 \pm 8,086$ & & &
\end{tabular}

In Table 2, while there was a significant difference in the scores of moral disengagement according to age variable (p $<0.05$ ), any significant difference was not observed in aggression scale sub-dimensions ( $p>0.05$ ).

Table 3. T-Test Results of Moral Disengagement and Aggression by Gender Variable

\begin{tabular}{lrrrrr}
\hline & Gender & $\mathrm{n}$ & Mean \pm Std. Dev. & $\mathrm{t}$ & $\mathrm{p}$ \\
\hline Physical & Female & 88 & $18,250 \pm 6,144$ & $-2,894$ &, $004^{*}$ \\
Aggression & Male & 119 & $20,756 \pm 6,172$ & & \\
Verbal & Female & 88 & $11,306 \pm 3,699$ & $-2,599$ &, $010^{*}$ \\
Aggression & Male & 119 & $12,722 \pm 3,999$ & &
\end{tabular}

In Table 3, while significant difference was observed in the physical and verbal aggression dimensions of the aggression scale according to gender variable ( $\mathrm{p}<0.05$ ), there was no significant difference in the moral disengagement scale in line with gender ( $\mathrm{p}>0.05)$.

Table 4. Anova Analysis Results of Moral Disengagement and Aggression Scale According to the Variable of Sports Year

\begin{tabular}{lrrrrrr}
\hline & & $\mathrm{n}$ & Mean \pm Std. Dev. & $\mathrm{F}$ & $\mathrm{p}$ & Tukey \\
\hline \multirow{3}{*}{ Moral } & $1-2$ & 54 & $25,388 \pm 10,996$ & & & $1-2$ years / 3-4 \\
Disengagement & $3-4$ & 51 & $20,411 \pm 7,782$ & 3,778 &, $011 *$ & years \\
& $5-6$ & 49 & $21,306 \pm 9,181$ & & & $1-2 / 7$ years \\
& 7 and above & 53 & $20,320 \pm 7,582$ & & & and above \\
\hline
\end{tabular}

In Table 4, while significant difference was seen in moral disengagement scores according to sports year variable (p $<0.05)$, significant difference was not observed in the sub-dimensions of aggression scale ( $p>0.05)$.

Table 5. T-Test Results of Moral Disengagement and Aggression by the Variable of Branch

\begin{tabular}{lrrrrr}
\hline & Branch & $\mathrm{n}$ & Mean \pm Std. Dev. & $\mathrm{t}$ & $\mathrm{P}$ \\
\hline \multirow{2}{*}{ Physical Aggression } & Taekwondo & 143 & $18,937 \pm 6,247$ & $-2,622$ &, $009^{*}$ \\
& Kick box & 64 & $21,375 \pm 6,032$ & & \\
Anger & Taekwondo & 143 & $15,923 \pm 5,162$ & $-3,723$ &, $000^{*}$ \\
& Kick box & 64 & $18,781 \pm 4,971$ & &, $001^{*}$ \\
Hostility & Taekwondo & 143 & $18,349 \pm 5,571$ & $-3,524$ &, $009^{*}$ \\
\multirow{2}{*}{ Verbal Aggression } & Kick box & 64 & $21,281 \pm 5,437$ & &, $002^{*}$ \\
& Taekwondo & 143 & $11,643 \pm 3,993$ & $-2,651$ & \\
Moral Disengagement & Kick box & 64 & $13,187 \pm 3,585$ & & \\
& Taekwondo & 143 & $20,559 \pm 8,743$ & $-3,204$ & \\
& Kick box & 64 & $24,890 \pm 9,518$ &
\end{tabular}

In Table 5, significant difference was detected in the sub-dimensions of the aggression scale and the moral disengagement scale according to the branch variable $(\mathrm{p}<0,05)$. The aggression and moral disengagement scores of kickboxers are higher than the scores of the taekwondo athletes.

Table 6. Correlation Analysis Results of the Scales

\begin{tabular}{cccccc}
\hline Scales & & $\begin{array}{c}\text { Physical } \\
\text { Aggression }\end{array}$ & Anger & Hostility & $\begin{array}{c}\text { Verbal } \\
\text { Aggression }\end{array}$ \\
\hline Moral & $\mathrm{p}$ &, $417^{* *}$ &, $349^{* *}$ &, $365^{* *}$ &, $315^{* *}$ \\
Disengagement & $\mathrm{r}$ &, 000 &, 000 &, 000 &, 000 \\
& $\mathrm{~N}$ & 207 & 207 & 207 & 207 \\
\hline
\end{tabular}

According to the correlation analysis shown in Table 6, moderate positive significant correlation between moral disengagement and aggression was detected. 


\section{Discussion and Conclusion}

Totally 207 athletes, 88 female and 119 male, from the branches of taekwondo and kickbox included in this study conducted with the purpose of investigating the moral disengagement and aggression levels of fight sport athletes according to several independent variables and reveal the relationship among them. It was determined that the majority of the participants were high school graduates and had low-income levels.

When the mean values of the scales are examined, it is seen that while the mean of physical aggression and hostility of athletes was found as the highest, verbal aggression had the lowest mean value within the sub-dimensions of aggression, and they stated that they somewhat disagreed with the moral disengagement. In accordance with these, it can be said that fight sport athletes may perform physical violence-related behaviours with hostility thoughts such as suspicion and anger, however, they do not somewhat agree with moral disengagement behaviours.

According to age, significant difference was found against the ages of 17-18 years in the dimension of moral disengagement. It can be stated that younger athletes show more moral disengagement behaviours than the older athletes. It can be considered that this may originate from the fact that the younger athletes are more inexperienced and could not adopt the moral philosophy of sport. Altin and Ozsari (2017) urged that the mean score of athletes in the 11-13 age group was found to be higher than the one in the 14-16 and 17-19 age groups in the dimension of adopting trick related to age factor, and this change was indicated as statistically significant. It can be stated that this situation is similar in our study with the fact that the mean scores of younger athletes for moral disengagement were higher. In this manner, it can be urged that younger athletes perform more moral disengagement behaviours to equalise balances, obtain unfair advantage and win. In our study, no significant difference was found in the dimensions of aggression scale by age. Significant difference was not also observed in the study by Kafali, Hunkar, Kececi ve Demiray (2017) in the dimension of aggression according to age as similar to the result that we found.

According to the year of sports, significant difference was detected in the dimension of moral disengagement against 1-2 years. Therefore, it can be uttered that as the experience of athletes increases, the behaviour of moral disengagement decreases, in other words, less experienced athletes perform more behaviours of moral disengagement.

Significant difference was found against male in the dimension of physical and verbal aggression according to gender. It can be stated that male athletes dealing with martial arts perform behaviours of physical and verbal aggression more than females. In the parallel of this study, Gurpinar (2014) also indicated that females adopted trick and competition less than male, and maintained to win fairly more. Thus, it can be suggested that male athletes performed more violence-oriented behaviours such as hitting, fighting and vandalising, and they have differences in their opinions or do not avoid from quarrel or dispute at the place that they show above-mentioned behaviours. Kafali, Hunkar, Kececi and Demiray (2017) indicated in the parallel of our study that the level of male is higher than female in all factors of aggression and in total. According to Kafali, Hunkar, Kececi and Demiray (2017), when this case is considered in terms of anthropology, it may be explained with gender roles attributed to men since the primitive age. Ersan, Dogan and Dogan (2009) found different results than our study and when the mean scores of aggression subscales were compared by gender, the difference between the scores of females and males was not statistically significant. In our study, significant difference was not detected in the dimension of moral disengagement according to gender. Similar to our study, Akandere et al. (2009) argued in their investigation that there was no difference in moral judgment levels of students in accordance with their gender. Moreover, in a study conducted by Akkoglu, Ayyildiz and Sunay (2019), although there was no statistically significant difference between athletes' fair play behaviours and their levels of moral disengagement in sports, the scores of male for moral disengagement were found to be higher than females. According to the study conducted by Mikail, Yaman and Altun (2017), although fair play behaviour was not statistically significant in line with gender, fair play scores of female participants were higher than male.

A significant difference was found in the dimension of aggression and moral disengagement against kickboxers according to the branch. Therefore, it can be said that those who perform kickboxing are more aggressive than those who do Takvando sports.

It can be uttered in this manner that those who perform kickboxing show more aggressive behaviours than those who do Takvando sports, and their behaviours for moral disengagement is higher. In this regard, it can be said that the athletes, who perform kickbox requiring more power, hardness and technic and done more freely, produce more aggressive behaviours and go further away athletic virtue and morality than the athletes doing taekwondo that is indicated as the way for becoming calm. Gurpinar (2014) argued in his study in line with the literature review that the moral decision-making attitude scores of the students who are engaged in football is lower than the other branches. In addition, the moral decision-making attitude scores of the students dealing with volleyball are higher than the students doing other sports and this case was explained as follows; the individuals doing contactless sports adopted trick and competition less than the ones performing contacted, and protected to win fairly more.

Akçakoyun, Calıskan and Karli (2010) found in their study conducted for comparing the empathy levels of athletes 
engaged in team and martial sports that there was not significant difference among groups concerning the variables such as gender, sports branch and year of sport. What is more, Sofia and Cruz (2017) argued that the athletes with the high level of physical contact and the ones with lower or younger competition categories were in the tendency to become more aggressive than athletes with lower contact and higher competition levels. It was concluded in the study carried out by Kafali, Hunkar, Kececi and Demiray (2017) that the aggression level of athletes engaging with individual sports was higher than the ones dealing with team sports in terms of the factors of Aggression, Hostility and in total. Kafali, Hunkar, Kececi and Demiray (2017) urged that this result may originate from the fact that team sport athletes could continue to show social behaviour during sports activities while individual sports athletes could not share their inner world with anybody else by becoming alone with himself/herself. Tutkun, Guner, Agaoglu, and Soslu (2010) concluded that individual athletes were more aggressive than team athletes.

It was then detected that there was a moderate positive significant relationship between all sub-dimensions of the aggression scale that is anger, hostility, physical and verbal aggression dimensions and Moral disengagement. Accordingly, as moral disengagement increases, aggression behaviours show increase, too. In other words, it can be suggested that while the number of negative behaviours that are performed by fight sport athletes in the name of gaining advantage and winning or forced by coaches increase, this leads to show more aggressive and moral disengagement behaviours. Yucel, Atalay and Gurkan (2015) contend that club managers, referees, athletes and coaches should perform prudent approaches and show actions and statements encouraging people to sports within the frame of fair play, love, respect and brotherhood. When considering the studies with similar results to this study, Yildirim and Abakay (2015) indicated that communication skills should be increased to reduce the behaviours of hostile and passive aggression and enhance the behaviour of assertiveness. Turksoy Isim, Guvendi and Turhan (2019) concluded that there is a low positive significant correlation between Moral disengagement and performance climate. The same investigators also urged that athletes who are focused on beating and overcoming his/her opponent, may perform behaviours that would injure the spirit of competition. Akoglu, Ayyldiz and Sunay (2019) stated that the higher participants have levels of moral disengagement, the less they perform fair play behaviours.

To conclude, it can be said that although fight sport athletes do not agree with moral disengagement, the aggressive behaviours increase as it is disengaged from morals. Moreover, aggressive behaviours reduce in individuals engaging with martial arts as a result of decrease in moral disengagement behaviour with increasing age and experience in the sport. It was concluded in the study conducted by Turksoy Isim, Guvendi and Toros (2019) that the success environment created by the coaches of athletes affects the moral decision-making status of athletes. If coaches condition their athletes to win, the possibility of seeing athletic virtue and moral behaviour in sports is decreasing according to Turksoy Isim, Guvendi and Toros (2019).

In this manner, it is considered that providing various trainings, which could support to increase sportsmanship behaviours, such as fair play, sportsmanship, ethical rules in sports and penalties to be met may contribute in reducing the behaviours of aggression and moral disengagement especially for inexperienced and younger athletes engaging with fight sports and their adopting to compete under the control of ethical committees in sports.

\section{References}

Abanoz, E. I., \& Soyer, F. (2018). A study with regard to the effect of sport on social values. Journal of Human Sciences, 15(1), 309-318. https://doi.org/10.14687/jhs.v15i1.4951

Akandere, M., Baştuğ, G., \& Güler, E. D. (2009). Effect of participation in sports on moral development of child in secondary school. Niğde University Journal of Physical Education and Sport Sciences, 3(1), 59-68.

Akçakoyun, F., Çalışkan, E., \& Karlı, H. (2010). The comparison of empathy levels of martial artists and team sportsmen. Turkish Kick Boxing Federation Journal of Sport Science, 3(2), 36-47.

Akoğlu, H. E., Ayyıldız, E., \& Sunay, H. (2019). Investigation of moral disengagement in sport and sportspersonship behavior of athletes participating in international sport organizations. 2. World Congress of sport sciences researches, 21-24 March 2019, Manisa/Turkey

Albouza, Y., d'Arripe-Longueville, F., \& Corrion, K. (2017). Role of Resistive Self-Regulatory Efficacy and Moral Disengagement in the Relationship between Values and Ag gressiveness in Athletes. Int. J. Behav. Res. Psychol. 5(1), 208-216.

Altın, M., \& Özsarı, A. (2017). The moral decision making attitudes of the athletes attending to sport training centers International Journal of Cultural and Social Studies, 3(1), 133-145.

Arslan, B. (2018). Examination of Moral Decision-Making Attitudes of Bocce and Darts Athletes in Turkey. Master's Thesis. Bartın University Education Teaching Science of Physical Education and Sport, Bartın.

Boardley, I. D., \& Kavussanu, M. (2008). The Moral Disengagement İn Sport Scale-Short. Journal of Sports Sciences, 
26(14), 1507-1517. https://doi.org/10.1080/02640410802315054

Buss, A. H., \& Perry, M. (1992). The Aggression Questionnaire. J. Pers. Soc. Psych., 63(3), 452-459. https://doi.org/10.1037/0022-3514.63.3.452

Erşan, E. E., Doğan, O., \& Doğan,S. (2009). The evaluation from point of view sociodemographic variables of the levels of aggression in the students of College of Physical Education and Sports. Cumhuriyet Med J, 31, 231-238.

Garay, F. R., Carrasco, M. A., \& Amor, P. J. (2016). Aggression, anger and hostility: Evaluation of moral disengagement as a mediational process. Personality and Social Psychology, 57(2), 129-135. https://doi.org/10.1111/sjop.12270

Görgüt, İ., \& Tuncel, S. (2017). Adaptation of sport character scale to turkish. Spormetre, 15(3), 149-156.

Gürpınar, B. (2014) Attitudes to moral decision making of the student athletes in secondary and high school level according to sport variables. Education and Science, 39(176), 413-424. https://doi.org/10.15390/EB.2014.3645

Gürpınar, B. (2015). Adaptation of the moral disengagement in sport scale-short into turkish culture: a validity and reliability study in a turkish sample. Ankara Üniv Spor Bil Fak, 13(1), 57-64.

Hemphill, D. (2009). Performance Enchancement and Drug Controlin Sport: Ethical Considerations. Sport in Society, 12(3), 313-326. https://doi.org/10.1080/17430430802673668

Johnson, C. G., Vargas, T. M., Watson, J. C., \& Pedersen, W. C. (2018). Coaching Efficacy, Moral Disengagement, and Responses To Hostile Aggression Among High School Coaches. International Journal of Sports Science \& Coahing, 5. https://doi.org/10.1177/1747954118787065

Kafal, S., Hünkar, İ., Keçeci, O., \& Demiray, E. (2017). The investigaton of aggression levels of athletes who do individual sport and team sport. The Journal of International Social Research, 10(50), 36-390.

Karasar, N. (2012). Bilimsel Araştırma Yöntemi. Ankara: Nobel

Madran, A. D. (2012). Reliability and Validity of the Buss-Perry Aggression Questionnaire-Turkish Version. Türk Psikiyatri Dergisi, 23, 1-6.

Mikail, T. E. L., Yaman, Ç., \& Altun, M. (2017). Opinions of Sports Faculty Students on Sportsmanship Behavior. International Journal of Cultural and Social Studies (IntJCSS), 3(2), 16-26.

Özbaydar, S. (1983). Insan Davranışlarının Sinırları ve Spor Psikolojisi. İstanbul: Altın Kitaplar.

Shields, D. L., Funk, C. D., \& Bredemeier, B. L. (2015). Predictors of Moral Disengagement in Sport. J Sport Exerc Psychol, 37(6), 646-658. https://doi.org/10.1123/jsep.2015-0110

Sofia, R., \& Cruz, J. F. A. Unveiling anger and aggression in sports: The effects of type of sport, competitive category and success level. Journal of Sport Psychology, 26(2), 21-28.

Tekin, G., Aykora, E., Bozac1, S., \& Eliöz, M. (2010). Comparison of the loneliness levels of martial artists and team sportsmen. Turkish Kick Boxing Federation Journal of Sport Science, 3(2), 28-36.

Tel, M. (2014). Fair play in turkish social life. International Journal Of Science Culture and Sport, 2(1), 694-704. https://doi.org/10.14486/IJSCS139

Türksoy Işım, A., Güvendi, B., \& Toros, T. (2019). Amateur league footballers' moral disengagement in sport, motivational climate and decision-making. International Journal of Social Sciences and Education Research, 5(1), 54-62. https://doi.org/10.24289/ijsser.483295

Tutkun, E., Güner, B. Ç., Ağaoğlu, S. A., \& Soslu, R. (2010). Evaluation of aggression levels of individuals participating in team and individual sports. Journal of Sports and Performance Researches, 1(1), 23-29.

Yıldırım, A., \& Abakay, U. (2015). Investigation of the relationship between hockey players' communication skills and aggression levels. Inonu University, Journal of Physical Education and Sport Sciences, 2(1), 17-28.

Yıldırım, Ş. (2016). Investigation of people's moral attitude who came to the sports center. Master's Thesis. Mehmet Akif Ersoy University Education Teaching Science of Physical Education and Sport, Burdur.

Yücel, A. S., Atalay, A., \& Gürkan, A. (2015). Factors affecting violence and aggression in sports. International Journal of Psychiatry And Psychological Researches, 2(2), 68-90. https://doi.org/10.17360/UHPPD.201529603

\section{Copyrights}

Copyright for this article is retained by the author(s), with first publication rights granted to the journal.

This is an open-access article distributed under the terms and conditions of the Creative Commons Attribution license which permits unrestricted use, distribution, and reproduction in any medium, provided the original work is properly cited. 